\begin{tabular}{|c|l|}
\hline Title & Observation of Three Phase Interface during Hydrogen Electrode Reactions in Unitized Regenerative Fuel Cell \\
\hline Author(s) & Majima, Wataru; Matsushima, Hisay oshi; Fukunaka, Y asuhiro; Ueda, Mikito \\
\hline Citation & $\begin{array}{l}\text { Journal of The Electrochemical Society, 161(10), F1002-F1005 } \\
\text { https://doi.org/10.1149/2.0391410jes }\end{array}$ \\
\hline Issue Date & 201407-09 \\
\hline Doc URL & http://hdl.handle.net/2115/57426 \\
\hline Type & article \\
\hline File Information & JECS161-10 F1002-1005.pdf \\
\hline
\end{tabular}

Instructions for use 


\title{
Observation of Three-Phase Interface during Hydrogen Electrode Reactions in Unitized Regenerative Fuel Cell
}

\author{
Wataru Majima, ${ }^{a}$ Hisayoshi Matsushima, ${ }^{b, z}$ Yasuhiro Fukunaka, ${ }^{a, *}$ and Mikito Ueda ${ }^{b, *}$ \\ ${ }^{a}$ Graduate School of Energy Science, Kyoto University, Sakyo-ku, Kyoto 606-8501, Japan \\ ${ }^{b}$ Faculty of Engineering, Hokkaido University, Sapporo, Hokkaido 0608628, Japan
}

\begin{abstract}
The dynamic behavior of the meniscus of a potassium hydroxide and sulfuric acid droplet on a platinum electrode was studied using a charge-coupled device (CCD) camera and confocal laser microscopy. The three-phase interface was investigated during the hydrogen oxidation reaction (HOR) and the hydrogen evolution reaction (HER). Contact angle measurements revealed a spreading interface during the HER whereas the droplet shape remained unchanged during the HOR for both droplets. The overhead view revealed the formation of many fine droplets near the meniscus boundary during the HOR in the alkaline electrolyte, which agrees with previous results for the oxygen reduction reaction (ORR). The correlation of these observations with electrochemical data and differences in the results between the HOR and the HER suggest that the motion of the meniscus was induced by local pH and temperature gradients, presumably caused by a non-uniform reaction because of the limitations of the dissolved gas.

(C) 2014 The Electrochemical Society. [DOI: 10.1149/2.0391410jes] All rights reserved.
\end{abstract}

Manuscript submitted May 27, 2014; revised manuscript received June 26, 2014. Published July 9, 2014.

Hydrogen is an attractive energy source as an alternative to fossil fuels. ${ }^{1-4}$ Hydrogen can be produced from water and used in fuel cells. No toxic gases are generated and thus energy shortages and environmental problems can be prevented. Unitized regenerative fuel cells (URFCs) are ideal energy devices. ${ }^{5-7}$ They function by generating electricity as fuel cells and they produce hydrogen gas by water electrolysis. They are compact and economic because common electrodes may be used. However, URFCs require highly controlled wettability and this is dependent on the operational mode. A hydrophobic nature is desired for the fuel cell mode and a hydrophilic is required for water electrolysis. Therefore, intrinsic interfacial properties make it difficult to improve the energy conversion efficiency.

The complex interface consists of an electrode (solid), an electrolyte (liquid), and a gas (air) and this is referred to as the three-phase interface, which is an essential part of the relevant electrochemical reaction. The meniscus plays an important role in controlling the reaction rate..$^{8-13}$ Inaba et al. reported that the hydrogen oxidation reaction (HOR) was affected by the shape of the meniscus, which determines the diffusion path of the dissolved gas. ${ }^{14}$

With an alkaline electrolyte, interesting interfacial phenomena have been observed. ${ }^{15-21}$ In a previous study, we observed an in situ meniscus motion during the oxygen reduction reaction (ORR) and the oxygen evolution reaction (OER) on a platinum electrode. ${ }^{17}$ A spread of the three-phase interface during the ORR was observed and the role of hydroxide ions in determining the surface tension was investigated.

To clarify the mechanism of this dynamic motion, in this study we measured the contact angle using different electrolytes and gas atmosphere used in a previous study. The relationship between the wettability and the electrochemical reaction of the HOR and the hydrogen evolution reaction (HER) is thus discussed in detail.

\section{Experimental}

The experimental apparatus and method have been described in our previous paper. ${ }^{17}$ The main points were mentioned here. The working electrode was a disk-shaped platinum sheet $(\phi 42 \mathrm{~mm} \times 0.1 \mathrm{~mm})$, and the counter electrode was a palladium electrode $(\phi 4 \mathrm{~mm}$ $\times 0.1 \mathrm{~mm}$ ). The center of the platinum disk was perforated and a palladium wire was attached at the perforation. The platinum electrode was polished with $1.0-, 0.3-$, and $0.05-\mu \mathrm{m}$ alumina powder. The reference electrode was a palladium wire $(\phi 0.5 \mathrm{~mm}, 99.99 \%$, Nilaco Corp.). All the potential values mentioned in this paper are referenced to this wire. Before the measurements, all electrodes were ultrasonically cleaned in ethanol and in purified water for 5 min each.

*Electrochemical Society Active Member.

${ }^{\mathrm{z} E}$-mail: matsushima@eng.hokudai.ac.jp
Hydrogen gas was fully absorbed onto the palladium electrodes by the electrolysis method.

An aqueous potassium hydroxide solution or a sulfuric acid solution (Wako Pure Chemical Industries) were used as electrolytes. The solutions were degassed using pure hydrogen gas for $2 \mathrm{~h}$. A droplet from the syringe needle was placed over the center of the electrodes. Hydrogen gas was flowed at a rate of $100 \mathrm{~mL} \mathrm{~min}^{-1}$ during the experiments.

Electrochemical measurements (HZ-3000, Hokuto Denko Corp.) were performed in potentiostatic mode for $600 \mathrm{~s}$ at $298 \mathrm{~K}$. During the measurements, a side view of the droplet was recorded using a CCD camera and the overhead view was imaged by confocal laser scanning microscopy (VK-X100, Keyence) with a helium neon laser $(633 \mathrm{~nm})$.

\section{Results and Discussion}

The time variation of the contact angle at the open circuit potential (OCP) was measured to study the effect of $\mathrm{pH}$. An electrolyte solution of $\mathrm{H}_{2} \mathrm{SO}_{4}(0.5 \mathrm{M})$ or a solution of $\mathrm{KOH}(0.001 \mathrm{M}, 0.01 \mathrm{M}, 0.36 \mathrm{M}$ or $4.46 \mathrm{M}$ ) was dropped onto a platinum plate under a hydrogen atmosphere. Figure 1 shows the contact angle $600 \mathrm{~s}$ after dropping. The angle decreased with an increase in $\mathrm{pH}$ and a steady-state value was obtained $(\mathrm{pH}>13)$. The contact angle under hydrogen gas was a few degrees lower than that under oxygen. ${ }^{17}$ This indicated that platinum became more hydrophilic under hydrogen, which inhibited the formation of the oxide surface layer. ${ }^{22,23}$

Two aqueous solutions of $0.36 \mathrm{M} \mathrm{KOH}$ and $0.1 \mathrm{M} \mathrm{H}_{2} \mathrm{SO}_{4}$ were chosen as a model electrolyte of alkaline and acid, respectively. An anodic potential was applied to the platinum electrode. Hydrogen was oxidized on the electrode when using the alkaline electrolyte $\left(\mathrm{H}_{2}\right.$ $\left.+2 \mathrm{OH}^{-} \rightarrow 2 \mathrm{H}_{2} \mathrm{O}+2 \mathrm{e}^{-}\right)$and the acidic electrolyte $\left(\mathrm{H}_{2} \rightarrow 2 \mathrm{H}^{+}\right.$ $+2 \mathrm{e}^{-}$). We refer to this as the fuel cell mode.

A confocal microscope image was obtained of the top of the meniscus rims when in fuel cell mode. Fig. 2 shows sequential images of the alkaline droplet when the electrode potential was set to $-0.2 \mathrm{~V}$. The black area demonstrated the shadow of the droplet and the bright one was dry electrode surface. The arrow in Fig. 2 indicated the meniscus rim. The formation of many fine drops in front of the meniscus rim was clearly observed at $600 \mathrm{~s}$. The size and number of the drops increased with an increase in the anodic potential. Although fine drops were present during the ORR, ${ }^{17}$ no creeping motion of the meniscus rim was observed at any potential.

The fine drops are attributed to condensation from the water vapor phase upon exposure to the cold metal. The condensation was probably caused by a difference in the water vapor pressure associated with a temperature or concentration gradient. ${ }^{24}$ The rate of the HOR depends on the electrode's position. Therefore, the reaction occurs preferentially at the meniscus where the dissolved gas can diffuse 


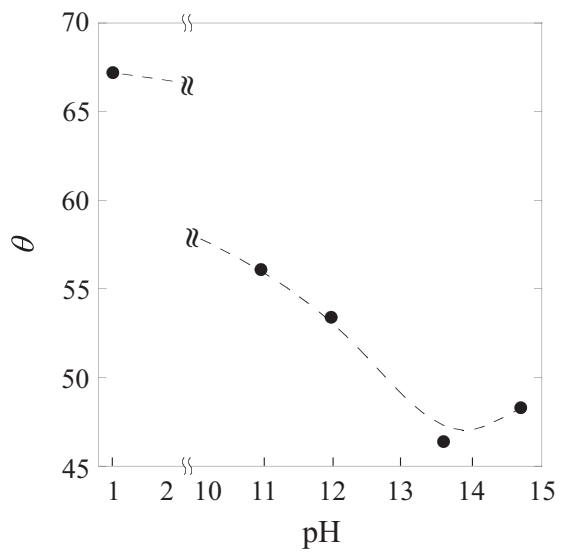

Figure 1. Contact angle of a droplet as a function of $\mathrm{pH}$ on a platinum electrode at the open circuit potential under a hydrogen atmosphere.

through the short path between the gas/liquid interface and the electrode. This generates a heterogeneous current distribution between the meniscus rim and the center of the electrode. It has been reported that the difference in vaporization rate is more important than the concentration gradient. The solution with a lower $\mathrm{KOH}$ concentration near the meniscus rim was easily vaporized. ${ }^{25}$

The contact angle of the alkaline and acidic droplets was measured using side view images from the CCD camera. Fig. 3 shows the time variation of the contact angle when several anode potentials were applied. The contact angle of both the alkaline and acidic droplets decreased slowly by a few degrees for $600 \mathrm{~s}$. The angle values did not depend on the potential. The values of the alkaline droplet were in the range of $50^{\circ}-60^{\circ}$, and these were smaller than those of the acidic droplet $\left(60^{\circ}-65^{\circ}\right)$.

The $\mathrm{pH}$ of the meniscus changes slightly because the HOR consumes hydroxide ions from the alkaline solution and produces proton in the acidic solution. From the dependence of $\mathrm{pH}$ on the contact angle, the wettability of the meniscus should have a hydrophobic tendency. However, we obtained unexpected results. The variation in $\mathrm{pH}$ is likely too small to change the contact angle. Furthermore, the weight of the droplet causes difficulties in lifting the droplet interface.
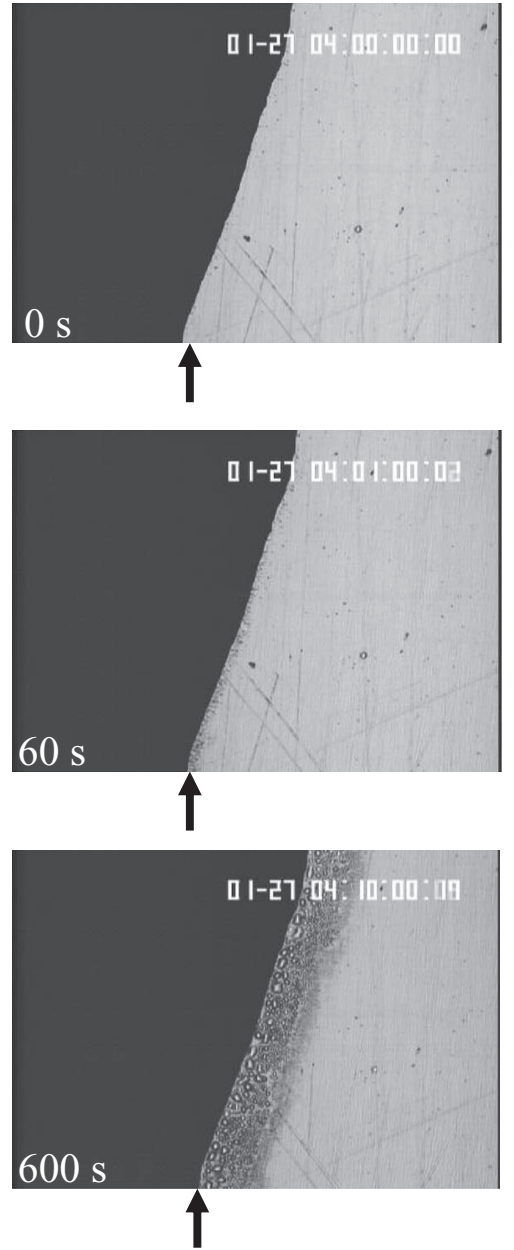

Figure 2. Sequence of images of the front view, obtained by confocal laser microscopy, showing the meniscus rim of the alkaline droplet under a hydrogen atmosphere when the electrode potential was set to $-0.2 \mathrm{~V}$.

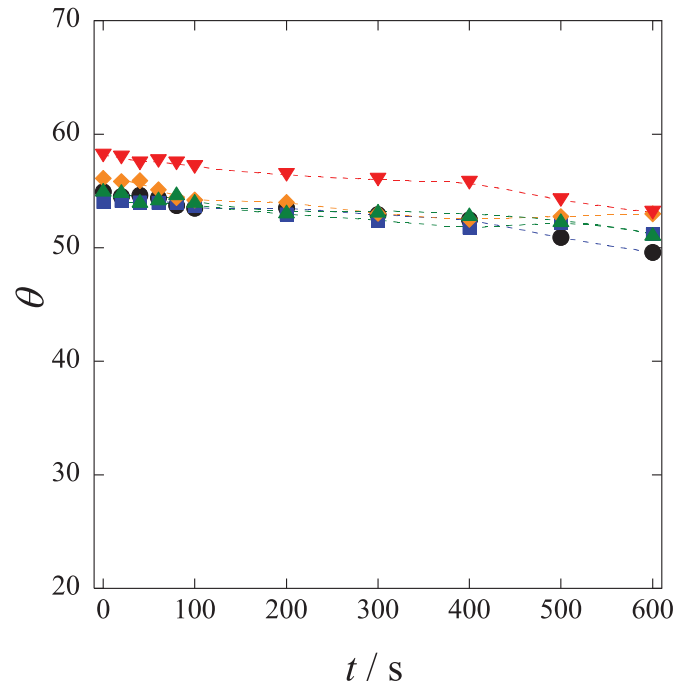

(a)

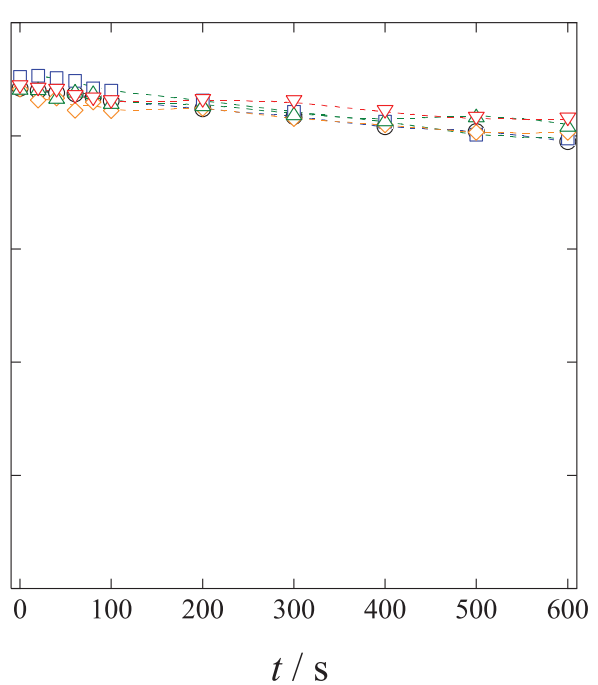

(b)

Figure 3. Time-dependent changes in the contact angle of (a) $0.36 \mathrm{M} \mathrm{KOH}$ and (b) $0.5 \mathrm{M} \mathrm{H}_{2} \mathrm{SO}_{4}$ droplets during the HOR obtained at several electrode potentials. (๑: OCP, $\mathbf{\square}:-0.2 \mathrm{~V}, \diamond: 0 \mathrm{~V}, \mathbf{\Delta}: 0.2 \mathrm{~V}, \mathbf{\nabla}: 0.4 \mathrm{~V}$ in (a)) (०: OCP, $\square: 0.1 \mathrm{~V}, \diamond: 0.2 \mathrm{~V}, \triangle: 0.3 \mathrm{~V}, \nabla: 0.4 \mathrm{~V}$ in (b)). 


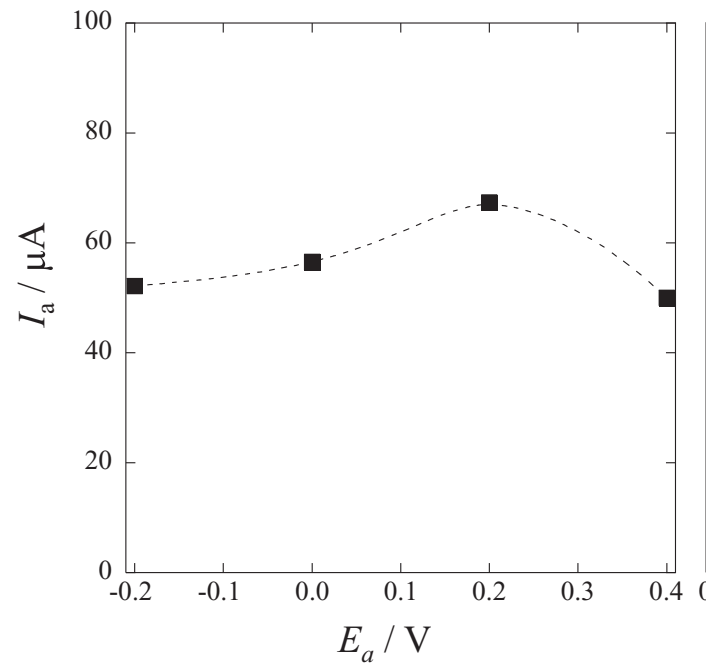

(a)

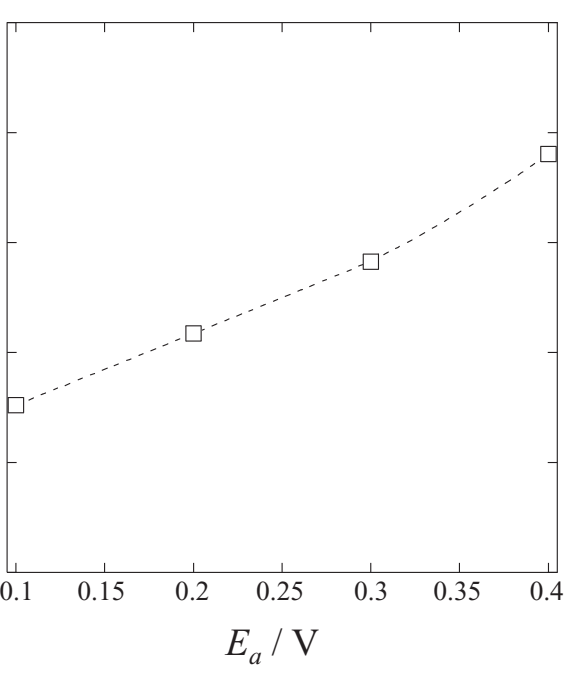

(b)

Figure 4. Potential vs. anodic current obtained $600 \mathrm{~s}$ after starting the HOR in (a) $0.36 \mathrm{M} \mathrm{KOH}$ and (b) $0.5 \mathrm{M} \mathrm{H}_{2} \mathrm{SO}_{4}$ droplets.

Fig. 4 shows potential-current curves at $600 \mathrm{~s}$ in (a) the alkaline solution and (b) the acidic solution. The anodic current of the alkaline electrolyte (Fig. 4a) does not depend on electrode potential. This suggests that the reaction is controlled by a mass transport limitation. In fact, as soon as the measurement was started the current decreased sharply for $40 \mathrm{~s}$. The dissolved hydrogen gas was quickly consumed and the concentration was diluted because of the slow dissolution process or because of the diffusion rate of the dissolved gas.

Conversely, the current in the acidic electrolyte increased with an increase in anodic potential (Fig. 4b). The dissolved gas was supplied to the reaction site efficiently. The reaction was dominated by an electron transfer limitation under the current test conditions.

The same experimental conditions as those for the fuel cell mode were used with the exception that a cathodic potential was applied to the working electrode. This led to the evolution of hydrogen gas by the reduction of water in the alkaline electrolyte solution $\left(2 \mathrm{H}_{2} \mathrm{O}+2 \mathrm{e}^{-}\right.$ $\rightarrow \mathrm{H}_{2}+2 \mathrm{OH}^{-}$) and the evolution of protons in the acidic electrolyte solution $\left(2 \mathrm{H}^{+}+2 \mathrm{e}^{-} \rightarrow \mathrm{H}_{2}\right)$. We refer to this as the water electrolysis mode.
Fig. 5 shows the time variation of the contact angle during the HER when electrolysis was carried out at several cathodic potentials. The angle decreased with an increase in the cathodic potential in both electrolytes. In the alkaline electrolyte, the meniscus rim rapidly crept onto the surface and the droplet became flat at around $50 \mathrm{~s}$ (Fig. 5a). This agrees with our previous results for the ORR. A common point for both the HER and the ORR is the elevation of $\mathrm{pH}$. The concentration of hydroxide ions in the meniscus can be attributed to the lower surface tension. ${ }^{26,27}$ The contact angle of the acidic droplet did not change between the OCP and $-0.5 \mathrm{~V}$ while at $-0.9 \mathrm{~V}$ it decreased from $60^{\circ}$ to $40^{\circ}$ (Fig. 5b). The meniscus rim at $-0.9 \mathrm{~V}$ gradually crept on the surface.

Fig. 6 is a plot of the cathodic current $600 \mathrm{~s}$ after electrolysis upon the application of several potentials. Contrary to the fuel cell mode in the alkaline electrolyte, the HER was not dominated by mass transport. The contact area increased upon droplet depression. Moreover, some microscopic convection was apparent because of gas bubble evolution. ${ }^{28-30}$ The convection likely assisted in the mixing of the solution in the meniscus and in the removal of surface-blocking bubbles.

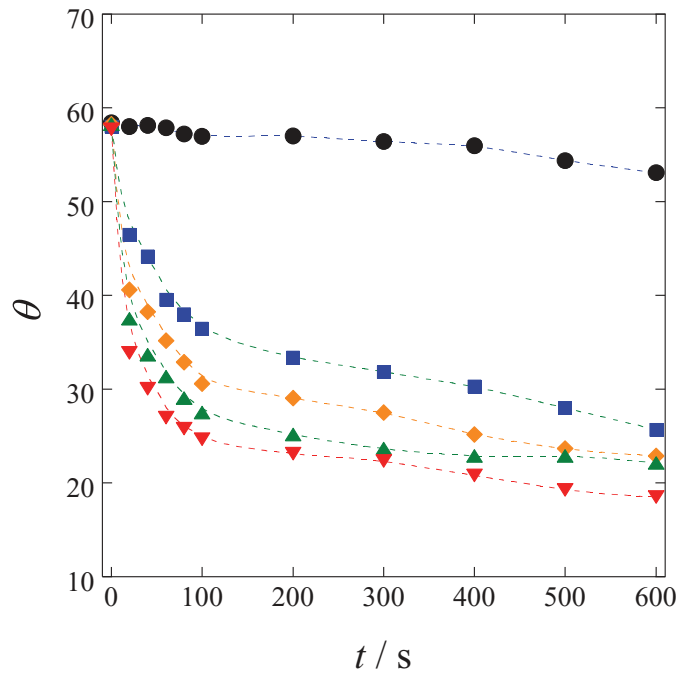

(a)

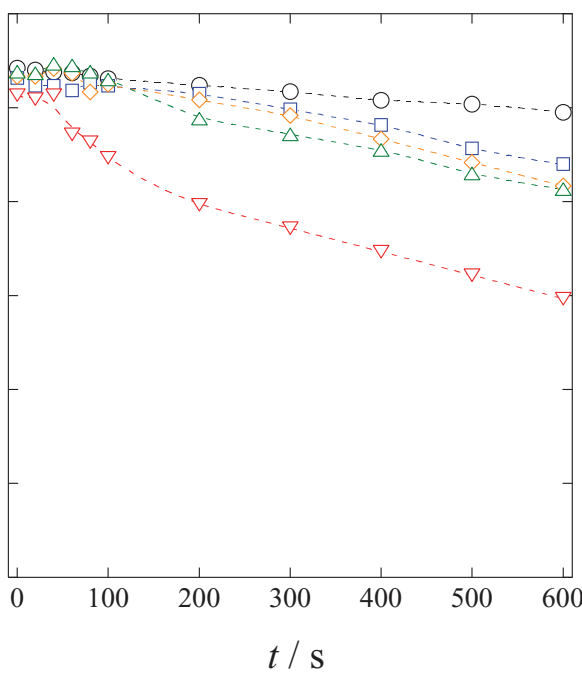

(b)

Figure 5. Time-dependent changes in the contact angle of (a) $0.36 \mathrm{M} \mathrm{KOH}$ and (b) $0.5 \mathrm{M} \mathrm{H}_{2} \mathrm{SO}_{4}$ droplets during the HER obtained at several electrode potentials. $(\bullet:$ OCP, $\mathbf{\square}:-0.7 \mathrm{~V}, \diamond:-0.9 \mathrm{~V}, \mathbf{\Delta}:-1.1 \mathrm{~V}, \mathbf{\nabla}:-1.3 \mathrm{~V}$ in (a)) (०: OCP, $\square:-0.3 \mathrm{~V}, \diamond:-0.5 \mathrm{~V}, \triangle:-0.7 \mathrm{~V}, \nabla:-0.9 \mathrm{~V}$ in (b)). 


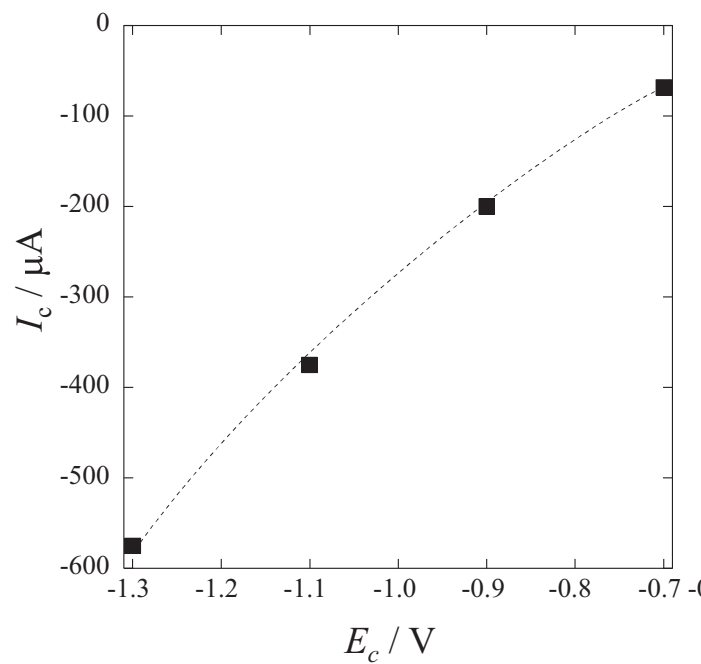

(a)

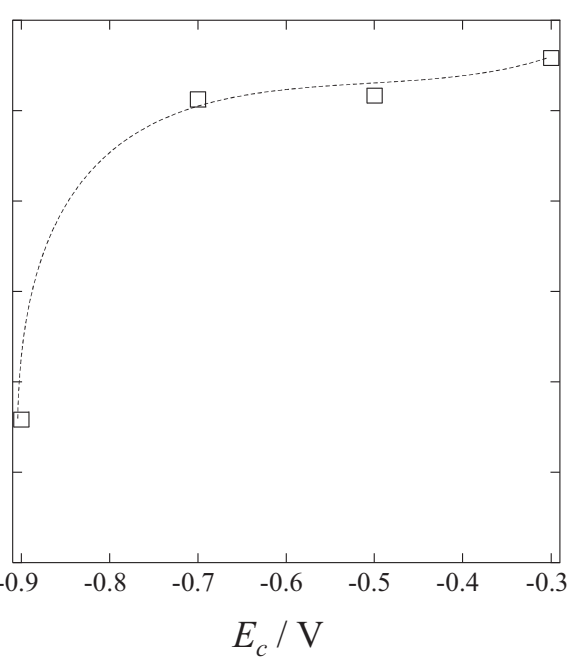

(b)

Figure 6. Potential vs. cathodic current obtained $600 \mathrm{~s}$ after starting the HER in (a) $0.36 \mathrm{M} \mathrm{KOH}^{2}$ and (b) $0.5 \mathrm{M} \mathrm{H}_{2} \mathrm{SO}_{4}$ droplets.

In the acidic solution, the HER current was constant regardless of electrolysis time and cathode potential except at $-0.9 \mathrm{~V}$ (Fig. 6b). The small cathodic current can probably be attributed to the high overpotential. The HER was not very noticeable under the present conditions. This explains the independence of the contact angle from the potential (Fig. 5b). Once the electrode potential overcame the overpotential, the current remarkably increased with an increase in the cathode potential $(<-0.7 \mathrm{~V})$, at which the concentration of protons in the meniscus decreased and the three phase interface became hydrophilic.

\section{Conclusions}

In situ observations of the droplets presented here clearly demonstrate a dynamic motion of the meniscus and the formation of fine droplets on a platinum electrode, and this correlated well with the HOR and the HER. In addition to the ORR, the spread of the threephase interface during the HER is explained by $\mathrm{pH}$ elevation, which can reduce surface tension. The motion of the meniscus in the alkaline droplet was more prominent than that of the acidic droplet, and this is attributed to the large overpotential of the HER. The hydrophilic property during the HER enhanced the cathodic current because of the short diffusion path of dissolved hydrogen gas and the apparent increase in the reaction area. In contrast, the rate of the HOR did not increase when using an alkaline droplet, which suggests a mass transfer limitation.

\section{References}

1. M. Carmo, D. L. Fritz, J. Merge, and D. Stolten, Int. J. Hydrog. Energy, 38, 4901 (2013).

2. K. Mazloomi and C. Gomes, Renew. Sust. Energ. Rev., 16, 3024 (2012).
3. K. Zeng and D. K. Zhang, Prog. Energy Combust. Sci., 36, 307 (2010).

4. M. Balat, Int. J. Hydrog. Energy, 33, 4013 (2008).

5. S. Altmann, T. Kaz, and K. A. Friedrich, Electrochim. Acta, 56, 4287 (2011).

6. S. A. Grigoriev, I. G. Shtatniy, P. Millet, V. I. Porembsky, and V. N. Fateev, Int. J. Hydrog. Energy, 36, 4148 (2011).

7. J. Pettersson, B. Ramsey, and D. Harrison, J. Power Sources, 157, 28 (2006).

8. G. Sakuma, Y. Fukunaka, and H. Matsushima, Int. J. Hydrog. Energy, 39, 7638 (2014).

9. J. R. Selman and P. H. Hsieh, Int. J. Hydrog. Energy, 37, 19270 (2012).

10. S. J. Lee, S. Kim, G. G. Park, and C. S. Kim, J. Power Sources, 185, 867 (2008).

11. M. Kawase, Y. Mugikura, and T. Watanabe, J. Electrochem. Soc., 147, 854 (2000).

12. Y. Mugikura and J. R. Selman, J. Electrochem. Soc., 143, 2442 (1996).

13. J. O. Bockris and B. D. Cahan, J. Chemical Physics, 50, 1307 (1969).

14. M. Inaba, M. Uno, J. Maruyama, A. Tasaka, K. Katakura, and Z. Ogumi, J. Electroanal. Chem., 417, 105 (1996).

15. Ph. Mandin, Z. Derhoumi, H. Roustan, and R. Wuthrich, Electrochim. Acta, 128, 248 (2014).

16. Z. Derhoumi, Ph. Mandin, H. Roustan, and R. Wuthrich, J. Appl. Electrochim., 43, 1145 (2013).

17. H. Matsushima, W. Majima, and Y. Fukunaka, Electrochim. Acta, 114, 509 (2013).

18. C. Iwakura, M. Horiuchi, S. Nohara, N. Furukawa, and H. Inoue, J. Appl. Electrochem., 35, 293 (2005).

19. M. Muramatsu and J. R. Selman, J. Electrochem. Soc., 139, 1255 (1992).

20. M. N. Hull and H. I. James, J. Electrochem. Soc., 124, 332 (1977).

21. R. H. Muller, J. Electrochem. Soc., 113, 943 (1966).

22. H. Matsushima, Y. Fukunaka, and K. Kuribayashi, Electrochim. Acta, 51, 4190 (2006).

23. H. Matsushima, T. Nishida, Y. Konishi, Y. Fukunaka, Y. Ito, and K. Kuribayashi, Electrochim. Acta, 48, 4119 (2003).

24. A. A. Franco, P. Schott, C. Jallut, and B. Maschke, J. Electrochem. Soc., 153, A1053 (2006).

25. D. N. Bennion and C. W. Tobias, J. Electrochem. Soc., 113, 589 (1966).

26. S. Lubetkin, Electrochim. Acta, 48, 357 (2002).

27. E. N. Lightfoot and V. Ludviksson, J. Electrochem. Soc., 113, 1325 (1966).

28. Ph. Mandin, R. Wuthrich, and H. Roustan, AIChE J., 56, 2446 (2010).

29. H. Matsushima, D. Kiuchi, Y. Fukunaka, and K. Kuribayashi, Electrochem. Commun., 11, 1721 (2009)

30. H. Vogt, Electrochim. Acta, 38, 1421 (1993). 